\title{
Discursos sobre a inclusão digital
}

\author{
Discourses on digital inclusion \\ Discursos acerca de la inclusión digital
}

RAQUEL GOULART BARRETO*

RESUMO - O presente artigo visa ao encaminhamento de questões relativas aos discursos acerca da inclusão digital e está estruturado em quatro seções. A primeira delas compreende um conjunto de reflexões acerca do título e das palavras-chave, no contexto da temática específica. A segunda é dedicada à análise de discurso na condição de alternativa teórico-metodológica para a aproximação do objeto inclusão digital. A terceira discute o par inclusão/ exclusão, questionando o pressuposto de que o primeiro elemento venha a superar o que tem sido posto como divisor digital nos vários sentidos assumidos pela expressão. Finalmente, a quarta seção sistematiza a análise da inclusão como escolha lexical em múltiplas combinações.

Palavras-chave - Análise de discurso. Tecnologia da informação e da comunicação. Democratização.

\begin{abstract}
The present article aims at questions concerning discourses on digital inclusion and is structured into four sections. The first one comprises a set of reflections about the title and the keywords in the context of the specific theme. The second is devoted to discourse analysis as theoretical-methodological alternative to approach digital inclusion object. The third discusses the pair inclusion/exclusion, questioning the assumption that the first element will overcome what has been put as digital divide, in several senses of the expression. Finally, the fourth section explores the analysis of 'inclusion' as a lexical choice in multiple combinations.
\end{abstract}

Keywords - Discourse analysis. Information and communication technology. Democratization.

RESUMEN - El presente artículo encamina cuestiones relativas a los discursos acerca de la inclusión digital y está estructurado en cuatro secciones. La primera de ellas compone un conjunto de reflexiones acerca del título y de las palabras clave, en el contexto del tema específico. La segunda se dedica al análisis de discurso en la condición de alternativa teórico-metodológica para la aproximación del objeto inclusión digital. La tercera discute el par inclusión/ exclusión, cuestionando la suposición de que el primer elemento venga a superar lo que ha sido puesto como divisor digital, en los varios sentidos de la expresión. Finalmente, la cuarta sección sistematiza el análisis de la inclusión como elección lexical en múltiples combinaciones.

Palabras clave - Análisis del discurso. Tecnología de la información y de la comunicación. Democratización.

\footnotetext{
* Doutora em Educação pela Universidade Federal do Rio de Janeiro (Rio de Janeiro, RJ, Brasil) e professora na Universidade Estadual do Rio de Janeiro (Rio de Janeiro, RJ, Brasil).E-mail: <raquel@uol.com.br>.
} 


\section{DA TEMÁTICA}

A escolha do título foi feita durante o processo de produção do texto, na tentativa de dar conta das principais relações que constituem o seu objeto, sublinhando as opções anteriores quanto ao modo de aproximação das questões envolvidas. No título, estão os dois substantivos fundamentais (discursos e inclusão), o movimento entre eles (sobre) e o adjetivo (digital). Com "discursos", marcadamente no plural, é apontada a pretensão de incluir diferentes perspectivas, não apenas no que se refere à relação entre discurso e "realidade", determinante na objetivação do primeiro termo, mas das leituras que têm sustentado a relação propriamente dita. Com "sobre", a proposta é trazer à discussão elaborações teóricas em disputa por hegemonia, em vez de buscar o que seria uma identificação definidora, através da preposição "de". Em "inclusão" está o núcleo sólido da abordagem e em "digital", a focalização presente. Assim, assumido o ponto de vista discursivo, o título também poderia ser: inclusão, uma escolha lexical em múltiplas combinações, aqui designando a seção final.

Com base nessa breve análise introdutória, estariam definidas pelo menos duas das palavras-chave do texto. Entretanto, o vocabulário controlado que constitui qualquer thesaurus impõe algum nível de deslocamento para que os descritores favoreçam a indexação e a recuperação das informações contidas no artigo. ${ }^{1}$ No caso, considerando a polissemia do termo "discurso", esta poderia mesmo não ser uma boa escolha. É importante reconhecer que, ainda que o sintagma completo ("análise de/do discurso") tenha sido "arrastado a uma circulação incontrolável" (MAINGUENEAU, 1989, p. 11), não deixa de remeter a algumas alternativas teórico-metodológicas reconhecidas, mesmo que inscritas em diferentes tendências.

Quanto à outra palavra-chave ("inclusão"), no conjunto das possibilidades abertas, apareceria como "educação inclusiva" e, no contexto brasileiro, tenderia a ser associada, imediata e indevidamente, ao atendimento aos portadores de necessidades especiais. Assim sendo, foram buscadas duas relações que favorecessem o objeto em questão: "tecnologias da informação e da comunicação" (TIC), para representar o adjetivo "digital", e "democratização", que deveria permanecer entre aspas, como demonstram os argumentos utilizados no desenvolvimento do artigo.

No processo de busca dos descritores adequados, significando já registrados, algumas questões merecem destaque. Uma delas está relacionada à confirmação dos caminhos já percorridos como registro do que seriam avanços do próprio conhecimento nas diferentes áreas, com fronteiras aparentemente bem delimitadas. A rigor, a julgar pelas palavras-chave, este artigo não pertenceria à área educacional stricto sensu, ainda que esta seja caracterizada pela recontextualização (BERNSTEIN, 1996; FAIRCLOUGH, 2006) de produções situadas em outras.

De novo, sem negar a importância dos movimentos de acesso e recuperação das produções, permanece a dúvida acerca do espaço para o registro das mudanças, paradigmáticas ou não, que marcam o conhecimento disponível. Em outras palavras, fica uma espécie de silêncio quanto à propriedade e à atualidade dos descritores consagrados.

Em se tratando do conhecimento disponível nos territórios em que este artigo se move, parece oportuna a referência ao teórico da comunicação Gaston Mattelart (2005) na sua análise do megaprojeto do Google, inscrito no sonho de uma nova biblioteca de Alexandria, através da digitalização dos acervos de algumas das maiores bibliotecas do mundo anglo-saxão e da sua colocação online gratuitamente: "Organizar a informação do mundo e torná-la universalmente acessível e útil” (p.3). O que acarreta o risco da imposição de um modelo único de estruturação dos conhecimentos por grandes sociedades transnacionais. Se cabe ao Google a tarefa de organizar a memória coletiva de que todos se utilizarão, será preciso contentar-se em aceitar uma forma de alienação cultural.

Diante da "Googlelização de tudo" (VAIDHYANATHAN, 2011), uma possível entrada no tema da inclusão digital é uma busca rápida do que está (sendo) dito a respeito. Em 0,39 segundo, foram encontrados aproximadamente 345 mil resultados. Feita a partir da expressão em língua inglesa, em 0,36 segundo, a busca gera aproximadamente 28,2 milhões de resultados. Passando mesmo que rapidamente por ambas, as concepções giram em torno de: "Inclusão digital é o nome dado ao processo de democratização do acesso às tecnologias da informação, de forma a permitir a inserção de todos na sociedade da informação".

De um lado, essa definição básica ratifica a escolha das duas palavras-chave aqui empregadas diante da ausência da expressão pretendida. De outro, os pronomes indefinidos "tudo" e "todos", registrados no parágrafo anterior, remetem à necessidade de pensar discursivamente a indefinição sugerida. A formulação retoma não apenas o sonho da biblioteca de Alexandria, mas o pressuposto de que todo o conhecimento produzido pela humanidade esteja disponível, como se não houvesse cada vez mais patentes e leis de propriedade intelectual protegendo o que é reconhecidamente estratégico. Além disso, se a "democratização do acesso às tecnologias da informação" permite a inserção de "todos" no contexto da dita "sociedade da informação", é razoável supor que todo e qualquer acesso às TICs autorize o uso das expressões "inclusão digital" e "social". 
Portanto, tendo em vista as questões aqui expostas, a análise de discurso será assumida como modo de aproximação da "inclusão digital".

\section{Da análise (crítica) de discurso como modo de aproximação do objeto}

Por se tratar do tema da inclusão, introduzem-se as questões discursivas a partir de dois exemplares de linguagem que podem ser chamados de clichês por estarem prontos para circular (FERREIRA, 1993) e terem sido frequentes há cerca de duas décadas, nas práticas cotidianas dos jovens. Um deles expressa a adesão entusiástica a diferentes proposições: "Tô dentro!". O outro, ao contrário, expressa a rejeição: "Me inclua fora dessa!". Neste, sem entrar em considerações de ordem gramatical, está marcada uma negação ao mesmo tempo atípica e enfática.

Por outro lado, por visar aos discursos "sobre" a inclusão, o núcleo sólido do presente artigo não é o discurso cotidiano, seja ele oral, escrito ou multimidiático, mas as elaborações teóricas e as suas consequências nas políticas formuladas em diferentes níveis, como condições de possibilidade que envolvem as dimensões simbólica e material. Essa última afirmação afasta a abordagem do discurso em si, apartado da realidade concreta em que está inscrito. Daí a qualificação (crítica) utilizada por Fairclough (2005) para caracterizar a rejeição à tendência de focalizar a dimensão estritamente discursiva na produção da análise. Ou seja, o discurso não é "tudo". À postura idealista atual, o autor contrapõe o modo de pensar as relações dialéticas entre o discurso e os outros elementos das práticas sociais.

Nesse ponto, parece oportuno sublinhar que Fairclough, no texto acima referido, não se atém ao grupo por ele capitaneado na Universidade de Lancaster, incluindo parte da escola francesa, representada por Michel Pêcheux, principal referência da vertente brasileira liderada por Eni Orlandi. Ao fazê-lo, não oblitera diferenças como, por exemplo, as relativas ao espaço atribuído ao sujeito ${ }^{3}$, mas permite abordar aproximações fundadas em alguns pressupostos e procedimentos.

Entre as referidas aproximações, está o pressuposto básico (FAIRCLOUGH, 2001, p.93) de que "a constituição discursiva de uma sociedade não emana de um livre jogo de ideias nas cabeças das pessoas, mas de uma prática social que está firmemente enraizada em estruturas sociais materiais, concretas, orientando-se para elas". Também vale destacar que não cabe a concepção de discurso como "atividade puramente individual ou reflexo de variáveis situacionais" (idem, p. 90), mas como modo de ação que, por sua relação dialética com a estrutura social, permite "investigar as práticas discursivas como formas materiais de ideologia" (idem, p. 116), objeto de análise ao final desta seção.
A obra acima referida constitui referência importante por contemplar pressupostos, princípios e procedimentos, mas ainda adota a nomenclatura "análise de discurso textualmente orientada", pouco esclarecedora, visto que não há análise de discurso que seja caracterizada pelo descolamento em relação ao texto. Afinal, é do texto, objeto empírico, que se parte em busca do discurso. Já a "análise crítica de discurso" (ACD) demarca diferença relevante, na medida da existência de propostas que se caracterizam por orientações paradigmáticas que pensam a linguagem desprovida de exterior (MCNALLY, 1999). $\mathrm{O}$ que a distingue de outras abordagens, vale insistir, é, antes de tudo, a sua inscrição no realismo crítico (FAIRCLOUGH, 2003), materializada na objetivação do discurso como prática social inseparável das demais, nas suas múltiplas determinações.

$\mathrm{O}$ autor propõe uma abordagem tridimensional do discurso, encarando-o como: (1) texto; (2) prática discursiva, envolvendo produção, distribuição e consumo; e (3) prática social. No que diz respeito ao trabalho analítico, a partir dos textos que constituem cada corpus específico, os pontos de entrada supõem a sua inscrição histórica e o trabalho com as pistas linguísticas detectáveis. Fairclough (2001) organiza as referidas pistas em três dimensões: (1) semântica; (2) sintática; e (3) pragmática. A primeira diz respeito às escolhas lexicais; a segunda, às relações entre as palavras escolhidas; e a última, às relações dos sujeitos com as formulações.

A dimensão que tem recebido maior atenção no conjunto das análises disponíveis, dentro e fora da ACD, corresponde à semântica, por serem as palavras usadas o ponto de entrada mais básico. Como exemplos das que não se inscrevem na vertente específica, Mattelart (2006, p. 241) aborda as questões relativas a vocabulário como "a batalha das palavras contra todos os desvios de seu sentido primitivo e das manipulações que as isolam de sua memória". O mesmo pode ser dito em relação a Bourdieu e Wacquant (2001), na exortação ao enfrentamento da despolitização implicada no "novo léxico", ou na "nova vulgata planetária" (p.2), em que termos como "capitalismo, classe, exploração, dominação e desigualdade" são banidos, sob pretexto de obsolescência ou impertinência, enquanto um vocabulário aparentemente sem origem e sem história circula cotidianamente: "globalização, flexibilidade, governabilidade, empregabilidade etc." Também Moraes $(2009$, p. 587) aponta para o necessário movimento de colocar em xeque

um novo vocabulário que ressignifica conceitos, categorias e termos, de modo a torná-los condizentes com os emergentes paradigmas que referenciam as pesquisas, reformas, planos e propostas para a educação brasileira e latino-americana. 
Para encaminhar questões como as expostas acima, Fairclough (2001) estabelece a distinção dos dois processos que sustentam os movimentos de abandono, apagamento e/ou apropriação de palavras em diferentes contextos e matrizes conceituais, assim como o de cunhagem de outras para dar conta de novos aspectos da "realidade": ressignificação e relexicalização.

A ressignificação é constituída pela atribuição de sentidos novos a palavras dicionarizadas, em deslocamentos e/ou esvaziamentos que as inscrevem em matrizes outras. É presença constante nos frequentes movimentos de recontextualização, caracterizada por Bernstein, já citado, tendo como referência o deslocamento de uma área para outra, assim como a dimensão de escala que Fairclough (2006, p. 101) lhe acrescentou, ao defini-la como "um fenômeno complexo, envolvendo, para além de uma simples colonização, um processo de apropriação cujas características e resultados dependem das circunstâncias concretas dos diversos contextos". ${ }^{4}$ Tem sido marcante na recontextualização educacional das TICs, nas formulações das organizações "globais" endereçadas aos estados nacionais, especialmente quando periféricos, desde que não se perca a perspectiva da complexidade do conceito em leituras lineares e mecânicas, de modo que o processo não inclua mediações, como as que serão discutidas adiante. Daí a importância de focalizar termoschave, como "educação" e "aprendizagem".

Por sua vez, a relexicalização, ou a nova lexicalização, compreende a produção de novos termos, sejam eles neologismos ou transposições dos já cunhados em outras áreas e para outros fins, para dar conta de sentidos que as palavras dicionarizadas supostamente não expressam. Assim, por exemplo, as desigualdades entre países tendem a não ser mais representadas como Primeiro e Terceiro Mundo, países desenvolvidos e em desenvolvimento, centrais e periféricos, ricos e pobres; mas subsumidas em Norte e Sul. Em lugar da demarcação das desigualdades, fica a alusão à coordenada geográfica, em um cenário enunciativo marcado pelo seu deslocamento para a condição de diferenças.

A segunda dimensão, sintática, compreende as relações entre as escolhas lexicais. Nela, merece especial destaque a constituição do sujeito das formulações, quer pela omissão da agência, escondendo e/ou legitimando diversas intervenções, quer como posição indevida, atribuída a um suposto agente que não poderia desenvolver as ações especificadas. No primeiro caso, análise circunstanciada pode ser encontrada em Barreto e Leher (2008), referida adiante. No segundo, variações em torno de "as tecnologias trazem" estão presentes em Magalhães (2008).

E a terceira dimensão, pragmática, corresponde às relações que os formuladores estabelecem com as formulações. Também denominada modalidade, expressa graus de comprometimento mais ou menos categóricos, através dos verbos auxiliares modais, como "dever" e "poder", dos advérbios de modo e dos próprios tempos verbais, além do recurso a expressões que indicam indeterminação ("uma espécie de"), e dos padrões típicos do discurso oral, como entonação.

Considerando as três dimensões, o formulador da ACD (FAIRCLOUGH, 2003, p.6-7) sintetizou nos seguintes termos as representações do "espaço-tempo global":

O espaço global é representado como uma entidade [...] o presente simples se torna 'indeterminado', representando passado e futuro apenas como datas pré e pós [...] A modalidade das representações acerca dos processos e relações no tempo-espaço global é epistêmica e categoricamente assertiva: afirmações sem qualquer modalização representam os processos como sendo reais, acontecendo [...] Os atores nos processos materiais são não-humanos, inanimados ('novas tecnologias', 'novos mercados') ou nominalizados ('mudança'), e o ator no processo verbal é 'este novo mundo'. O espaço-tempo global é representado como processos sem agenciamento humano.

A síntese acima, por sua vez, deve ser lida como expressão de tendências e não como simplificação das questões discutidas. Em primeiro lugar, porque não havendo discursos "puros", são muitas as hibridizações em jogo nos diferentes contextos. Em segundo, e especialmente importante para os propósitos deste artigo, porque favorece a abordagem das questões mais diretamente ligadas à ideologia.

Assumir as práticas discursivas como formas materiais de ideologia é um ponto de partida que, como tal, não dá conta das várias questões envolvidas, mas permite vislumbrar alternativas de aproximação baseadas no conceito gramsciano de hegemonia. $\mathrm{O}$ que as tendências discursivas permitem dimensionar são os movimentos de entrega e resistência dos sujeitos aos sentidos sedimentados e aos deslocamentos (ressignificações) possíveis. $\mathrm{Na}$ medida da constituição histórica da linguagem, não há como dissociá-la da sua base material, ainda que haja mudanças na vida social que sejam, em parte, alterações no discurso sem serem apenas discursivas. Ao mesmo tempo em que há mudanças discursivas que podem não apontar para mudanças sociais, como as de motivação retórica.

Em outras palavras, a caracterização de tendências discursivas não "resolve" as relações entre discurso e estrutura social, mas favorece a compreensão dos mecanismos que permitem que, em meio a muitos sentidos possíveis, um seja mais "lido" que os outros: 
seja formalizado e legitimado, enquanto os demais podem nem chegar a ser cogitados. Em outras palavras, do ponto de vista discursivo, a ideologia corresponde à hegemonia de sentido.

Em relação a outras perspectivas de ideologia, é relevante pontuar que nesta ela não é pensada como lacuna, falta ou vazio. Pelo contrário, é caracterizada pelo excesso de preenchimento, fazendo com que sentidos em luta por hegemonia acabem sendo apagados pela interpretação que parece única. É o caso da "inclusão", investida de valores sempre positivos, associados à "democratização", em versão mais performática. Nesse ponto, é fundamental enfatizar que a "performatividade" não é uma propriedade do discurso, mas um conjunto de condições de possibilidade que incluem aspectos semióticos e não semióticos, de materialidade mais espessa, como base da vida material, em relação de congruência.

Dizendo de outra maneira, essa abordagem demonstra que os embates não se resumem às práticas discursivas. Os modos da sua recontextualização dependem de fatores que as extrapolam, como mostram os encaminhamentos de Barreto e Leher (2008) no que se refere às relações entre os níveis macro e micro de análise. Objetivando as formulações do Banco Mundial para o ensino superior nos chamados países em desenvolvimento, expressas por "recomendações" ou mesmo por "condicionalidades", os autores discutem a traduções envolvidas nas formulações políticas a elas relacionadas, em nível nacional, regional e local. A base é uma só, mas as especificidades assumidas nos vários países derivam de condições de possibilidade também diversas. Assim, incluindo a recontextualização das TICs, a variação das condições concretas, incluindo as diretamente relacionadas a acesso, remete a formular propostas envolvendo deslocamentos feitos de adaptações.

Finalmente, na tentativa de sintetizar a dimensão histórica dos sentidos hegemônicos, duas palavras podem ser definidoras das formulações datadas de antes e depois da primeira metade dos anos 1990. A "democratização", com a polissemia que a caracteriza, é uma palavra de ordem que veio a ser substituída por "inclusão", como é possível observar no próprio índice remissivo de dois livros de Fairclough $(2001 ; 2006)$ aqui citados, lembrando que o primeiro foi publicado originalmente em 1992. Esse movimento, ainda que possa contar com outras hipóteses explicativas, não pode ser dissociado do caráter mais concreto do último termo, no contexto da valorização da "performatividade". Em outras palavras, se a "democratização" sugere desejo, disposição ou mesmo promessa sempre renovada, a "inclusão" implica inegavelmente algum nível de ação, a ser discutida nas seções seguintes.

\section{Inclusão/exclusão: superando o divisor digital?}

Falar de "inclusão" implica trazer para a cena discursiva a "exclusão". Ainda que o par, nas suas diferentes dimensões, seja objeto de análise na seção final, aqui será discutida a face mais performática, "visível", do movimento que sugere a superação de uma fronteira denominada divisor (brecha ou fratura) digital.

Historicamente, a expressão foi introduzida no vocabulário americano em meados dos anos 1990, referindo-se ao acesso desigual às TICs (LIGHT, 2001). Representava, por assim dizer, uma operação matemática simples, tendo no numerador a quantidade de pessoas com acesso a computador/internet em suas residências e, no denominador, a população total (PAIVA, 2010). Era, também simplesmente, uma questão de se ter ou não acesso às TICs.

Entretanto, a expressão foi sendo ressignificada pelo seu afastamento da concepção da desigualdade econômica entre grupos de pessoas. Ainda que não toque na questão específica, Pinkett (2001) acaba fornecendo uma indicação importante para abordá-la: a sua condição de direito civil chave no século XXI, no contexto norte-americano. Um dos seus desdobramentos tem sido o treinamento comunitário da habilidade de usar, de forma dita significativa, o computador e a internet. Como já apontado na referência a Magalhães (2008), não se trata mais da distinção simples entre os que têm e os que não têm acesso às TICs, mas do modo da sua incorporação educacional. Por outro lado, a ênfase na ação "comunitária" também favorece o afastamento do critério de disponibilidade doméstica, inevitavelmente referida às desigualdades de poder aquisitivo entre os sujeitos "incluídos" e "excluídos", bem como de disponibilização do serviço de banda larga para as diversas regiões. Nesses termos, a proliferação das lan houses tem uma dupla face: uma estratégia de "democratização" das TICs, que passou a ser posta como "inclusão", e o apagamento das condições desiguais para o exercício do novo direito civil.

No que tange aos modos de acesso, há outro nível de divisor digital operando a separação dos produtores e dos consumidores de conteúdo. Por mais que se tenha investido em aplicações facilitadoras da autoria, o conteúdo produzido em blogs públicos, por exemplo, envolve uma parcela diminuta da população dos usuários. Ao mesmo tempo, essa desigualdade serve para consolidar uma construção ideológica central: a de que todo o conhecimento produzido estaria disponível na internet.

Há, ainda, a questão da escala na recontextualização dos modos de acesso ao ser abordado o divisor digital global. As inegáveis assimetrias entre países e regiões comprometem o debate acerca do que seja o uso 
significativo da internet, viabilizando uma série de simplificações limitadas à dimensão técnica, ao mesmo tempo em que o discurso hegemônico, como no blog do Banco Mundial, incorpora alusões a uma abordagem "holística" e o elogio das "melhores práticas".

É importante assinalar que mesmo autores inscritos em formações discursivas distintas reconhecem os limites do debate na área, dada a ausência de reflexão sobre problemas sociais mais amplos. É o caso de Light (2001, p.711): “A tecnologia não é uma ferramenta neutra com efeitos universais, mas um meio com consequências que são significativamente moldadas pelo contexto histórico, social e cultural da sua utilização" (grifo da autora).

Aprofundando a discussão, Waller (2007, s/p) afirma que "o capital global subjugou a tecnologia aos seus próprios fins e vendeu o "milagre dos benefícios tecnológicos" ao mundo da educação". Tanto o alegado milagre quanto a sua venda são produzidos no enredo de políticas educacionais que atribuem às TICs o poder de converter "excluídos" em "incluídos".

Um bom exemplo tem sido a adesão entusiástica dos governos a programas como o OLPC (One Laptop per Child), idealizado pela organização não governamental homônima, presidida por Nicholas Negroponte, com equipamento desenvolvido pelo MIT (Massachusetts Institute of Technology). O projeto de inclusão digital tem sido associado à "transformação da sociedade através da educação", por meio da utilização de computadores portáteis menores do que os já existentes, barateados por medidas como a ausência de disco rígido. No site específico $^{6}$, além da caracterização da proposta, são contempladas histórias de sucesso narradas a partir de imagens. Entre elas, há um traço comum: o contraste entre o contexto pobre, muitas vezes rural, como na do Nepal, e o equipamento moderno, em primeiro plano.

Sem menosprezar a mudança inscrita nos contextos retratados, é importante sublinhar que as referidas imagens tendem a sugerir que o OLPC, sozinho, seja capaz de operar a transformação pretendida. É como se os laptops significassem a superação do "atraso" e da pobreza, hipótese que cai por terra diante da teoria trotskista do "desenvolvimento desigual e combinado" (LÖWY, 1998), analisando a convivência de formas modernas e arcaicas em cada processo socioeconômico, na união dialética entre o mais "avançado" e o mais "atrasado". ${ }^{7}$ Em vez de discursos acerca de expropriação e exploração do trabalho, são postos os da inclusão/ exclusão e do atraso/progresso como parâmetros do desenvolvimento. Unindo esses dois pares antinômicos estão as tecnologias, promovendo a modernização pela "democratização" do acesso à informação, incluindo os "excluídos" e supostamente transformando o atraso em progresso (BARRETO e LEHER, 2009).
A perspectiva das TICs como meio de superação do "atraso" corresponde à inclusão digital, como é possível verificar em diversos sites com reportagens sobre o OLPC, muitas vezes focalizando efeitos que extrapolam os educacionais. Em um deles, a despeito da força da imagem do menino e seu laptop junto a um bezerro preso próximo a um casebre, o tema é o aumento do comércio eletrônico na cidadezinha, explicitando a nem sempre assumida aliança entre tecnologias, informação e mercado. ${ }^{8}$

No que diz respeito ao Brasil, o governo aderiu ao programa, sob a sigla ProUCA(Programa Um Computador por Aluno), em algumas poucas escolas selecionadas para esse fim, com base em edital: projeto e número reduzido de alunos. O discurso da sua justificação segue a linha hegemônica da inclusão digital, embora não haja verba para a manutenção dos equipamentos, nem garantias de acesso à internet. A primeira ausência compromete a mobilidade, já que baterias viciadas não são substituídas, enquanto a segunda, em função do armazenamento nas nuvens, implica a exigência de constante e bom funcionamento da internet.

Em pesquisa realizada em uma escola do interior 9 , foram recebidos, em 2010, 559 computadores da marca CCE (Classmate), 15 dos quais chegaram com problemas e nunca puderam ser usados. Quanto aos demais, armazenados com muito capricho, parecendo mesmo novos, só funcionam conectados a tomadas. Além dessa dificuldade, a velocidade pífia (1 mega) disponível para toda a escola impede o trabalho com os equipamentos. Os alunos reclamam da lentidão e dos travamentos constantes, ao que os professores acrescentam questões relativas à legibilidade, considerando as dimensões reduzidas e a baixa qualidade da tela. Nas palavras de um aluno do 40 ano: "A professora usa o laptop dela em sala para mostrar vídeos baixados e os alunos fazem a interpretação no caderno". Alguns professores e alunos entrevistados afirmaram preferir os equipamentos domésticos.

Nesse ponto, talvez se pensasse em perguntar acerca do sentido da inclusão digital dos sujeitos envolvidos no macrocontexto brasileiro, "quarto país com mais nativos digitais do mundo", atrás da China, dos Estados Unidos da América do Norte e da Índia ${ }^{10}$. A resposta, ao contrário do que se poderia em princípio supor, precisaria levar em conta: do ponto de vista teórico, o desenvolvimento desigual e combinado; na perspectiva cultural e financeira, o fato de que os computadores se tornaram uma espécie de "eletrodoméstico da vez", custando menos que um aparelho de TV mais atual; e "pedagogicamente", a ausência de controle sobre o material circulante e sobre os usos dos computadores pessoais.

As aspas no último aspecto são justificáveis pela compreensão de que as políticas educacionais de inclusão 
digital têm sido caracterizadas por movimento que vai do hardware ao software. Em se tratando dos professores, uma primeira grande inflexão para intensificar o uso das TICs foi a distribuição de laptops, que começou em regime de comodato e passou a ser de doação. Pretendia atingir os professores, alunos e gestores, ampliando também a instalação de laboratórios de informática nas escolas, ainda que antigos problemas, como o de manutenção dos equipamentos, não tenham sido equacionados. ${ }^{11}$

A segunda grande inflexão corresponde a políticas de disseminação de materiais prontos, tidos como sendo de "excelência". No conjunto das iniciativas para disponibilizar sequências de ensino dos mais diversos conteúdos, as aulas prontas passaram a ser designadas como "objetos de aprendizagem". A escolha lexical é importante, na medida em que materializa a comodificação no "gerenciamento" do contato dos alunos com eles. Embora a expressão objetos de aprendizagem seja a tradução literal de learning objects, é importante lembrar que, na década de 1990, a expressão distance learning foi traduzida como "educação/ensino a distância". Logo, parece razoável supor que tenham mudado significativamente as condições de possibilidade de escolhas lexicais que denotem, sem preocupações, o esvaziamento do trabalho docente.

O movimento acima reforça a aposta nas TIC scomo "agentes" de transformação, na condição de hardware e de software, como tem demonstrado o investimento maciço nos diferentes objetos técnicos e na elaboração e/ou tradução de "aulas modelares". Fica configurada a inversão sintática radical: os objetos são deslocados para a posição de sujeitos das formulações.

Cabe destacar que, no discurso hegemônico, aqui representado pelo Banco Mundial, há mais de uma década era preconizada essa inversão (WORLD BANK, 2003). Na seção "Usando a tecnologia para transformar a aprendizagem", a inversão é posta como instituinte de um novo e necessário paradigma: "A aprendizagem precisa se tornar mais flexível e diferenciada para permitir mecanismos de distribuição alternativos" (p. 65). Logo, não se trata de propostas de ensino baseadas em alternativas teórico-metodológicas para favorecer a aprendizagem, mas da regulação desta pelos mecanismos de "distribuição". Central é "a emergência de novos fornecedores, oferecendo serviços diferentes de maneiras diferentes, representa uma oportunidade para os países em desenvolvimento" (idem, p. 55). Em outras palavras, a aprendizagem não é focalizada como processo interno, mas deslocada para a condição de acesso a "produtos dados", legitimando as propostas de substituição tecnológica, parcial ou total, e de avaliação unificada (BARRETO, 2012).
Em outro documento (WORLD BANK, 2011), este voltado para as estratégias a serem utilizadas no decênio 2011-2020, está a ressignificação radical da aprendizagem, no contexto da negação da escola como espaço privilegiado para a sua ocorrência, considerando especialmente a desigualdade social. Depois de reduzir educação a aprendizagem, o documento destaca, graficamente inclusive, que "para a maioria dos alunos, o aumento da escolarização não tem resultado em mais aprendizagem" (p.6). Nesses termos, a "aprendizagem para todos", marcada no título, coloca em xeque a propriedade do pronome indefinido.

A palavra "todos" tem sido uma escolha lexical recorrente, como em Universidade para Todos (ProUni) etc. Entretanto, não é possível afirmar que ela represente sequer a inclusão pretendida. Em muitos casos, fica evidente que "todos" são apenas "alguns" já privilegiados. É o que pode ser verificado, por exemplo, na crítica de Saviani (2007, p. 1252-3):

A lógica que embasa a proposta do 'Compromisso Todos pela Educação' pode ser traduzida como uma espécie de 'pedagogia de resultados': o governo se equipa com instrumentos de avaliação dos produtos, forçando, com isso, que o processo se ajuste às exigências postas pela demanda das empresas.

Que inclusão? Inclusão de quem? Inclusão em que termos? Como a inclusão é investida da condição de discurso nodal nesse tempo-espaço? São questões que sustentam a tentativa de sistematizar os argumentos presentes neste artigo.

\section{Inclusão: uma escolha lexical em múltiplas combinações}

A inclusão, originalmente referida à ausência de segregação dos sujeitos portadores de necessidades especiais, superando a noção de "deficiência" física ou mental, como Educação Inclusiva, vem sendo recontextualizada de múltiplas formas na "conversão de problemas da pobreza em problemas de exclusão social" (FAIRCLOUGH, 2006, p.25), já que a "exclusão", na dinâmica da nova forma de capitalismo, é "concebida como sendo mais residual, periférica e patológica do que endêmica" (idem, p. 89). Ainda de acordo com o autor, o enredo é o da "incapacidade de Estado de lidar com a pobreza, a não ser sob o pretexto limitado e inadequado da 'exclusão social', através de políticas de inclusão" (idem, p. 20).

Nas palavras de Pfeiffer (2011, p. 150): “As políticas públicas têm se revestido de políticas de inclusão que demarcam limites e margens, produzindo a manutenção da desigualdade como operadora das relações sociais". Dizendo de outra maneira, as políticas de inclusão não 
tocam nos mecanismos que produzem as desigualdades. Ao contrário, acabam por legitimá-los através de formulações autoritárias. Como afirma Cavallari (2014, p.25): “O processo de construção do saber sobre o excluído acaba por excluí-lo dessa construção, pois este é tomado como objeto do olhar e do saber do outro, cujo lugar enunciativo tem certo valor e reconhecimento social".

As políticas de inclusão não enfrentam os problemas da expropriação e da exploração, abandonando toda perspectiva de universalismo ao dirigir as ações do Estado a grupos particularistas, por meio de ações focais, instaurando uma espécie de círculo vicioso. Identificam os que serão alvo das ações como excluídos a serem beneficiados pela ação focal que irá elevá-los à condição de incluídos, significando que eles poderão deixar de ser alvo de ações focais posteriores (BARRETO e LEHER, 2009, p. 41).

Para analisar as políticas de inclusão, é preciso considerar o pressuposto da existência da exclusão. "Exclusão social ou luta de classes" é o embate de que parte Balibar (1992, p. 202), salientando: "Ninguém pode ser excluído do mercado, simplesmente porque ninguém pode dele sair, posto que o mercado é uma forma ou uma "formação social" que não comporta exterioridade". Assim, todos os trabalhadores expropriados, por mais miseráveis que sejam as suas condições de existência e de trabalho, estão já incluídos na esfera do capital.

Se a exclusão é contestada como pressuposto, os discursos acerca da inclusão perdem o sentido, ainda que a relação entre as condições materiais de vida e os direitos sociais, que compõem a linha imaginária incluídosexcluídos, seja altamente congruente (LEHER, 2012). O que está em jogo é a abordagem dos deslocamentos traduzidos em simplificações que servem para legitimar as bases do modo de produção capitalista na sua configuração atual.

Alguns deslocamentos são frágeis até mesmo do ponto de vista lógico-formal. Mattelart (2002), em História da sociedade da informação, aponta-os a partir da observação de que "a segunda metade do século XX foi marcada pela formação de crenças no poder miraculoso das tecnologias informacionais" (idem, p. 172), no "discurso salvador sobre a promessa de concórdia universal, de democratização descentralizada, de justiça social e de prosperidade geral" (idem, p.31), na convergência dos discursos apologéticos para "atestar o final dos grandes determinantes sociais e econômicos na construção dos modelos de implantação das tecnologias digitais e de suas redes" (idem, p. 146).

As tecnologias são centrais nos deslocamentos produzidos, corroborando a possibilidade do tratamento de aspectos mais visíveis da alardeada "inclusão". Os discursos que as acompanham e tentam justificar envolvem, até o presente momento, as duas qualificações básicas já registradas: inclusão digital e inclusão social. Entretanto, alguns desses discursos já contemplam complementos à qualificação. É o caso do Pimesp (Programa de Inclusão com Mérito no Ensino Superior Público Paulista) ${ }^{12}$, explicitando a perspectiva meritocrática assumida.

Outros complementos e estratégias discursivas poderão ser integrados à formulação. Aconteceu na ficção, em Animal farm, de George Orwell, cuja tradução é A revolução dos bichos, com o sétimo mandamento ("Todos os animais são iguais"), sendo acrescido de: "Porém alguns animais são mais iguais do que outros" (p. 92). Aconteceu, na política educacional brasileira, na recente votação do PNE (Plano Nacional de Educação), no Senado Federal. Como afirma Leher (2014, p. 1): ${ }^{13}$

\begin{abstract}
A data de aprovação, terça feira, 17 de dezembro de 2013, será lembrada como o dia em que o financiamento da educação pública brasileira teve a sua qualificação "público" apagada em prol das parcerias públicoprivadas, um anseio vivamente reivindicado pelas corporações "de novo tipo", que operam no setor de serviços educacionais e, avidamente, pelas coalizões empresariais imbuídas de um projeto de classe difundido como de salvação da educação brasileira.
\end{abstract}

As corporações, até então "excluídas" do acesso direto ao financiamento público, foram incluídas pela supressão do adjetivo. Discursos acerca da inclusão para a "justiça social" poderão vir a usar a ideologia da "salvação" como "argumento". Muitas aspas, acréscimos e supressões apontam para o fato de que, como já explicitado na segunda seção, o discurso é um modo de ação que, por sua relação dialética com a estrutura social, permite "investigar as práticas discursivas como formas materiais de ideologia" (FAIRCLOUGH, 2001, p. 116).

Em suma, o discurso não é inocente, nem desprovido de consequências.

\section{REFERÊNCIAS}

BALIBAR, Etienne. Les frontières de la démocratie. Paris: La Découverte, 1992.

BARRETO, Raquel Goulart; LEHER, Roberto. Do discurso e das condicionalidades do Banco Mundial, a educação superior "emerge" terciária. Revista Brasileira de Educação, Campinas, v. 13, n. 39, p. 423-436, set./dez. 2008. http://dx.doi. org/10.1590/S1413-24782008000300002

BARRETO, Raquel Goulart; LEHER, Elizabeth. O discurso da "inclusão". In: BARRETO, Raquel Goulart. Tecnologias, discursos, educação. Rio de Janeiro: EdUERJ, 2009. p. 39-58.

BARRETO, Raquel Goulart. A recontextualização das tecnologias da informação e da comunicação na formação e no trabalho docente. Educação \& Sociedade, v. 33, n. 121, p. 985-1002, dez. 2012. http://dx.doi.org/10.1590/S010173302012000400004 . 
BERNSTEIN, Basil. A estruturação do discurso pedagógico. Petrópolis, RJ: Vozes, 1996.

BOURDIEU, Pierre; WACQUANT, Loic. NewLiberalSpeak: notes on the new planetary vulgate. Radical Philosophy, 105, p. 2-5, 2001.

CAVALLARI, Juliana Santana. Equívocos que constituem o macrodiscurso político-educacional da inclusão. In: FERREIRA, Eliana Lucia; ORLANDI, Eni Puccinelli (Org.) Discursos sobre a inclusão. Niterói: RJ: Intertexto, 2014. p. $11-50$.

FAIRCLOUGH, Norman. Discurso e mudança social. Brasília, DF: Editora da UNB, 2001.

FAIRCLOUGH, Norman. Critical discourse analysis in researching language in the new capitalism: overdetermination, transdisciplinarity and textual analysis. 2003. Disponível em: $<$ http://www.ling.lancs.ac.uk/staff/norman/2003b.doc $>$. Acesso em: 10 jan. 2012.

FAIRCLOUGH, Norman. Critical discourse analysis. Marges linguistiques, n. 9, p. 76-94, 2005.

FAIRCLOUGH, Norman. Language and globalization. London: Routledge, 2006.

FERREIRA, Eliana Lucia; ORLANDI, Eni Puccinelli. (Org.) Discursos sobre a inclusão. Niterói, RJ: Intertexto, 2014.

FERREIRA, Maria Cristina Leandro. A antiética da vantagem e do jeitinho na terra em que Deus é brasileiro (o funcionamento discursivo do clichê no processo de constituição da brasilidade). In: ORLANDI, Eni Puccinelli (Org.). Discurso fundador. Campinas, SP: Pontes, 1993.

LEHER, Roberto. Educação no capitalismo dependente ou exclusão educacional? In: MENDONÇA, Sueli Guadelupe de Lima; SILVA, Vandei Pinto da; MILLER, Stela (Org.). Marx, Gramsci e Vigotski: aproximações. Araraquara, São Paulo: Junqueira \& Marín, 2012. p. 223-252.

LIGHT, J. S. Rethinking the digital divide. Harvard Educational Review , v. 71, n. 4, p. 709-733, 2001. http:// dx.doi.org/10.17763/haer.71.4.342x36742j2w4q82

LÖWY, Michel. A teoria do desenvolvimento desigual e combinado, outubro, $\mathrm{n}^{\circ} 1$, p. 73-80, 1998.

MAGALHÃES, Ligia Karam Corrêa. 2008. 275 f. Formação e trabalho docente: os sentidos atribuídos às tecnologias da informação e da comunicação. Tese (Doutorado em Educação) - Faculdade de Educação, Universidade do Estado do Rio de Janeiro, Rio de Janeiro, 2008.

MAINGUENEAU, Dominique. Novas tendências em análise do discurso. Campinas: Pontes-UNICAMP, 1989.

MATTELART, Armand. História da sociedade da informação. São Paulo: Loyola, 2002.

MATTELART, Armand. Sociedade do conhecimento e controle da informação e da comunicação. In: ENCONTRO LATINO DE ECONOMIA POLÍTICA DA INFORMAÇÃO, COMUNICAÇÃO E CULTURA, 5., 2005, Salvador. Disponível em: <http://www.gepicc.ufba.br/enlepicc/Armand MattelartPortugues.pdf $>$. Acesso em: 21 maio 2014.

MATTELART, Armand. Para que "nova ordem mundial da informação"? In: MORAES, Denis de (Org.). Sociedade midiatizada. Rio de Janeiro: Mauad, 2006. p. 233-246.
MCNALLY, David. Língua, história e luta de classe. In: WOOD, Ellen Meiksins; FOSTER, John Bellamy (Org.). Em defesa da história: marxismo e pós-modernismo. Rio de Janeiro: Jorge Zahar, 1999. p. 33-50.

MORAES, Maria Célia Marcondes de. "A teoria tem consequências": indagações sobre o conhecimento no campo da educação. Educação \& Sociedade, v. 30, n. 107, p. 585-607, maio/ago. 2009.

ORWELL, George. Animal farm. London: Longman, 1979.

PFIFFER, Cláudia Castellanos. Políticas públicas: educação e linguagem. Cadernos de Estudos Linguísticos, Campinas, v. 53, n. 2, p. 149-155, jul./dez. 2011.

PINKETT, Randall. Framing the digital divide. 2001. Disponível em: <http://tcla.gseis.ucla.edu/divide/politics $>$. Acesso em: 10 abr. 2014 .

SAVIANI, Dermeval. O Plano de Desenvolvimento da Educação: análise do Projeto do MEC. Educação \& Sociedade, v. 28 , n. 100, p. 1231-1255, out. 2007. http://dx.doi.org/10.1590/ S0101-73302007000300027

VAIDHYANATHAN, Siva. A googlelização de tudo (e por que devemos nos preocupar). São Paulo: Cultrix, 2011.

WALLER, Tim. ICT and social justice: educational technology, global capital and digital divides. The Journal for Critical Education Policies Studies (JCEPS), v. 5, n. 1, may 2007. Disponível em: <http://www.jceps.com/PDFs/05-1-11.pdf>. Acesso em: 15 abr. 2014.

WORLD BANK. Lifelong learning in the global knowledge economy: challenges for developing countries. 2003. Disponível em: <http://web.worldbank.org/WBSITE/EXTERNAL/ TOPICS/EXTEDUCATION/0,,contentMDK:20283504 menuPK:617592 pagePK:148956 piPK:216618 theSite PK:282386,00.html>. Acesso em: 21 abr. 2014.

WORLD BANK Education Strategy 2020: Learning for all: investing in people's knowledge and skills to promote development. 2011. Disponível em: <http://web.worldbank.org/ WBSITE/EXTERNAL/TOPICS/EXTEDUCATION/0, content MDK:22474207 menuPK:282402 pagePK:210058 piPK:21 0062 theSitePK:282386,00.html>. Acesso em: 22 abr. 2014.

\section{NOTAS}

${ }^{1}$ Cabe registrar que, durante o processo de elaboração do presente artigo, esteve indisponível o acesso à pesquisa do Thesaurus Brasileiro da Educação, em: <http://portal.inep.gov.br/pesquisa-thesaurus >

2 Cf. $<$ http://pt.wikipedia.org/wiki/Inclus\%C3\%A3o_digital $>$. Acesso em: 18 maio 2014

3 Para aprofundar este aspecto, ver o primeiro capítulo de Discurso e mudança social (2001), publicado na Inglaterra, em 1992.

4 Todas as traduções contidas neste artigo são da autora.

${ }^{5} \mathrm{Cf}$. $<$ http://blogs.worldbank.org/ic4d/digital-inclusion-beyond-access-tobroadband $>$. Acesso em: 13 maio 2014

${ }^{6}$ Cf. <http://one.laptop.org/>. Acesso em 20 abr. 2014.

7 Desautorizando discursos como o da existência de "dois Brasis" etc.

8 Disponível em: <http://in.reuters.com/article/2012/03/26/onlineshopping-india-retail-flipkart-re-idINDEE82M0GL20120326>. Acesso em: 16 abr. 2014.

9 Aqui não designada para preservar o anonimato.

$10<\mathrm{http}$ ://tecnologia.terra.com.br/internet/brasil-e-o-quarto-pais-com-maisnativos-digitais-do-mundo, $954 \mathrm{c} 7 \mathrm{ce} 29 \mathrm{~b} 7 \mathrm{~d} 1410 \mathrm{VgnVCM} 4000009 \mathrm{bcceb} 0$ aRCRD.html>. Acesso em: 28 maio 2014. 
${ }^{11}$ Por exemplo, de fevereiro de 2008 ao final de 2010, a Secretaria de Estado de Educação (SEEDUC-RJ) concluiu a meta de distribuição de, aproximadamente, 50 mil laptops aos professores de Ensino Fundamental I e II da rede.

${ }^{12} \mathrm{Cf}$. $<$ http://redeemancipa.org.br/wp-content/uploads/2013/02/PIMESP20-12-12.pdf>. Acesso em: 30 abr. 2014.
${ }^{13} \mathrm{Cf} .<$ http://portal.andes.org.br/imprensa/noticias/imp-ult-127759073. pdf $>$. Acesso em: 28 abr. 2014.

Artigo recebido em setembro 2015.

Aprovado em dezembro 2015. 